\title{
A Contribuição do CNJ Para a CONCRETIZaÇão da dignidade da PeSsoa HUMANA NO CONTEXTO DA ATUAÇÃO DO PODER JUDICIÁRIO
}

\author{
The CNJ contribution to the implementation of human dignity in the context of the \\ judiciary performance
}

\section{Déborah Leite da Silva}

Possui graduação em Direito pela Universidade Federal de Campina Grande (2004) e pós-graduação (lato sensu) em Direito Processual Civil também pela Universidade Federal de Campina Grande (2005). É professora efetiva da Universida do Estado do Rio Grande do Norte - UERN (desde julho de 2006), tendo assumido, também nessa instituição, a Coordenação do Núcleo de Prática Jurídica (desde fevereiro de 2009). Mestranda do Programa de Pós-Graduação em Direito da Universidade Federal do Rio Grande Norte. E-mail: deborahleitedasilva@yahoo.com.br.

\section{Walter Nunes da Silva JúNIOR}

Possui graduação em Direito pela Universidade Federal do Rio Grande do Norte (1987), mestrado em Direito Público pela Universidade Federal de Pernambuco (1999) e doutorado em Direito Constitucional pela Universidade Federal de Pernambuco (2006). Exerceu a função de membro do Conselho Nacional de Justiça (2009-2011), após o que retornou ao exercício da Titularidade da $2^{\text {a }}$ Vara Federal - Seção Judiciária do Rio Grande do Norte, sendo também, atualmente, Juiz Corregedor da Penitenciária Federal em Mossoró. É professor adjunto da Universidade Federal do Rio Grande do Norte e Conselheiro da Escola Nacional de Formação e Aperfeiçoamento de Magistrados - Enfam, para o biênio 2013/2014 . Tem experiência na área de Direito, com ênfase em Direito Processual Penal, atuando principalmente nos seguintes temas: direito processual penal, processo eletrônico e plano de gestão do judiciário. E-mail: waltersilva16@gmal.com.

RECEBIDO EM: 01.08.2013

APROVADO EM: 29.08.2013

\section{Resumo}

A atual conjuntura que permeia a criação e manutenção de institutos com vistas à consecução de interesses sociais deve levar em consideração, sobretudo, a viabilização dos interesses mais relevantes inerentes à pessoa humana, dos quais não poderá o indivíduo ser privado sem que isso implique em patente violação a todo um arcabouço principiológico-constitucional que o tutela. Nesse sentido, a dignidade 
da pessoa humana foi elevada à categoria de princípio-norte em muitos países, não apenas sob o viés interpretativo, mas também em relação à imposição de limites e à atribuição de responsabilidade aos poderes constituídos. É de se ressaltar que a viabilização do princípio referido se dá, em regra, pelo viés dos direitos fundamentais, e tem como um de seus desdobramentos a igualdade, sobretudo no seu aspecto substancial. Contudo, nem sempre se vislumbra o respeito ao ser humano quando da atuação estatal, o que também se dá no contexto do exercício da função jurisdicional, quando o próprio acesso à justiça é negado a quem necessita recorrer ao Judiciário, bem como o excesso de formalismo e as próprias dificuldades estruturais acabam retardando a entrega da prestação jurisdicional. Tal ordem se coisas consiste em transgressão flagrante à dignidade humana. O presente artigo possui como objeto a discussão da efetivação da dignidade humana e da igualdade material no contexto processual, para tanto analisando as inovações impulsionadas pela necessidade de dar concretude a tão relevantes princípios no contexto da realidade brasileira, dentre as quais se destaca a criação, levada a cabo pela Emenda Constitucional n ${ }^{\circ} 45 / 2004$, do Conselho Nacional de Justiça, órgão de controle externo do Poder Judiciário e de cunho administrativo-constitucional.

Palavras-chave: Dignidade da pessoa humana. Igualdade substancial. Conselho NACIONAL DE JUstiça.

\section{Abstract}

The present conjuncture that pervades the creation and maintenance of institutions that aim social interests must consider, overall, to make feasible the most relevant interests inherent to human being, which individuals cannot be deprived of or it will imply a violation of constitutional structure that supports them. In such sense, human being dignity has been raised up to a status of key-principle in several countries, not only by an interpretative view, but also as an imposition of boundaries and to the attribution of responsibilities to constituted powers. It must be stressed out that such principle is made feasible by fundamental rights bias, and has as one of its foldings equality, specially in its substantial aspect. However, not always envisions human respect when state action, which also occurs in the context of the exercise of the judicial function, when the proper access to justice is denied to those who need to turn to the courts, as well as excessive formalism and the very end structural difficulties delaying the delivery of judicial services. This order consists of things is blatant transgression of human dignity. The present article aims to discuss on how to turn effective human dignity and material equality in the law sue context, both analyzing innovations propelled by the necessity to fulfill such relevant principles in the Brazilian reality context, among which we stress the creation of the Conselho Nacional de Justiça, made real by the Constitutional amendment n. 45/2004, an Judiciary power external control organism with both administrative and constitutional aims. 
Keywords: Dignity of the human Person. Substantive equality. Conselho NacioNAL DE JUSTIÇA.

Sumário: 1. Da dignidade da pessoa humana. 2. Princípio da igualdade. 3. O processo como corolário dos direitos fundamentais. 3.1. Dos óbices ao direito fundamental de acesso à justiça. 3.2. Das "ondas" de acesso à justiça. 3.3 Dos instrumentos viabilizadores da concretização do acesso à justiça. 4. O Conselho Nacional de Justiça como instrumento viabilizador da dignidade da pessoa humana. 4.1. Da caracterização do Conselho Nacional de Justiça. 4.2. Dados estatísticos que corroboram a imprescindibilidade da atuação do CNJ. Conclusão. Referências.

\section{INTRODUÇÃo}

É inegável que os direitos inerentes ao ser humano inspiram o estabelecimento das relações jurídicas, tenham estas caráter público ou privado, fazendo surgir obrigações de cunho positivo ou negativo.

Há de se destacar que o atual status de que gozam os direitos acima referidos foi possível a partir de uma reformulação da maneira como o indivíduo é visto no contexto social onde se encontra inserto, resultando, no período pós-guerra, na concepção antropocêntrica e evoluindo para uma concepção mais coletiva, onde o ser humano, apesar de respeitado quanto à sua individualidade, passou a ser concebido como engrenagem de uma grande máquina, a sociedade.

Nesse contexto, uma série de direitos que antes lhe eram negados passaram não apenas a ser considerados, mas a inspirar os ordenamentos jurídicos internos de diversos países, bem como instrumentos normativos de caráter internacional, a exemplo dos tratados.

De fato, por não exigirem o preenchimento de qualquer outro requisito que não a condição de ser humano, a sua titularidade é universal, e, embora alguns ordenamentos insistam em negá-los, a sua transgressão deve implicar em severa responsabilização, inclusive a nível internacional, o que teria o condão de possibilitar a relativização da soberania estatal.

Ressalte-se que um dos principais desdobramentos dos direitos humanos é o princípio da igualdade. No entanto, não é suficiente que essa igualdade seja meramente formal, ou seja, tão somente prevista ou tutelada normativamente pelos ordenamentos jurídicos dos países. Para que possa instrumentalizar a consecução da dignidade humana, a igualdade deve ser concebida no seu aspecto substancial, tornando possível o tratamento diferenciado em um contexto em que os sujeitos estão 
em posições não isonômicas e, desse modo, garantindo paridade de oportunidades.

O princípio da isonomia tem aplicabilidade ampla e deve ser invocado sempre que a efetivação de regras abstratas e alheias a uma análise mais aprofundada da realidade que visa tutelar o exija. Não se trata, como inicialmente se poderia imaginar, de atribuir vantagens desarrazoadas a um dos sujeitos envolvidos na relação, entregando-lhe, por esse meio, o direito que pleiteia, mas de permitir que disponha das mesmas ferramentas atribuídas ao seu opositor para lutar pelo que acredita lhe pertencer.

No âmbito processual não há como se afastar a aplicabilidade do princípio da isonomia no seu viés substancial. Até porque, por ser o processo instrumento viabilizador do reconhecimento de direitos, e a decisão dele oriunda passível de exigibilidade coercitiva, a todos deve ser dada igual oportunidade de utilização do instrumental processual e, desse modo, de convencimento do magistrado.

Contudo, percebe-se que a dignidade da pessoa humana nem sempre é respeitada quando da atuação estatal, inclusive ao exercera função jurisdicional, o que se torna muito claro no momento em que as partes necessitadas de recorrer ao Judiciário não conseguem efetivamente ter acesso ao mesmo ou, ainda que transponham uma série de obstáculos, dentre eles econômicos, educacionais e burocráticos, não recebem de forma tempestiva a prestação jurisdicional. Tal ordem de coisas, indubitavelmente, viola a sua dignidade, na medida em que as impede de manejar adequadamente o instrumental processual a fim de que os bens dos quais são titulares possam ser resguardados, em um contexto em que elas estarão obrigadas a recorrer a tal Poder estatal quando não conseguiram obter, de forma consensual ou extrajudicialmente, aquilo que almejam.

Nesse sentido, há se destacar que algumas medidas já foram adotadas, a exemplo da isenção de custas para os que se declararem pobres; a implementação das Defensorias Públicas e dos Juizados Especiais; a instituição de ações coletivas e de regramentos específicos para categorias reconhecidamente vulneráveis, a exemplo do consumidor e trabalhador.

Acrescente-se, ainda, as inovações introduzidas pela Emenda Constitucional $n^{0} 45 / 2004$, sobretudo ao viabilizar a criação do Conselho Nacional de Justiça, órgão de natureza administrativa, vinculado ao Poder Judiciário e que tem contribuído consideravelmente para o aperfeiçoamento da prestação jurisdicional estatal, a partir de uma atuação estratégica, que se materializa no estabelecimento de metas, na padronização de procedimentos, bem como no reforço da responsabilização disciplinar dos magistrados, na medida em que tem a competência concorrente com as corregedorias para agir nessa seara.

Ressalte-se, no entanto, que os mecanismos acima elencados não são considerados suficientes para a solução de tão intricada problemática, até porque a isenção de custas resta inócua diante da falta de conscientização dos titulares de direitos em relação às ferramentas que podem manejar para viabilizá-los. Outrossim, as De- 
fensorias Públicas ainda padecem de efetiva implementação na maioria dos estados brasileiros e a atuação do CNJ, apesar de expressiva,contribuirá, mais a longo prazo, para uma reestruturação do Judiciário.

Diante do contexto acima apresentado, a discussão acerca da concretização da dignidade da pessoa humana no âmbito processual é não apenas relevante, mas, sobretudo, atual, razão pela qual é objeto do presente artigo.

\section{Da dignidade da pessoa humana}

A expressão Dignidade da Pessoa Humana, sob o aspecto etimológico, deriva do latim dignus, significando "aquele que merece estima e honra, aquele que é importante" (MORAES, 2003, p. 112).

Apesar da dificuldade de se buscar a definição de dignidade humana, considerando-se que, muitas vezes, esse termo está atrelado a aspectos de ordem moral, há de se considerar que as atuais Constituições de muitos países a elegeram como princípio informativo e elemento viabilizador da concretização de outros relevantíssimos direitos, tais como a igualdade e a liberdade.

Ressalte-se que a realidade acima narrada se consolidou a partir do pósguerra, como uma necessidade de superação das consequências deixadas por um período de explícita violação aos direitos mais basilares do ser humano. Posteriormente, a Declaração Universal dos Direitos Humanos foi elaborada, influenciando os ordenamentos constitucionais de diversos países, que, a exemplo de Portugal, passaram a mencionar, de forma expressa, a necessária proteção à Dignidade da Pessoa Humana (NOVAIS, 2011, p. 51).

Sob o aspecto jurídico, o princípio ora em análise serve não apenas de parâmetro interpretativo dos direitos fundamentais, mas como elemento definidor dos limites de atuação do Estado em relação ao indivíduo, o que o obriga a não apenas obedecê-lo, mas a viabilizar a sua proteção em face de terceiros.

Nesse contexto, percebe-se a existência de um movimento de colocação do ser humano, individualmente considerado, como elemento central, visão que pode ser atribuída ao cristianismo (MORAES, 2003, 112), cabendo ao Estado, ente formal, assegurar-lhe os direitos. Desse modo, de acordo com Novais, "[...] o Estado é instrumento que não existe para si, mas que serve as pessoas individuais, assegurando e promovendo a dignidade, autonomia, liberdade e bem-estar dessas pessoas concretas" (NOVAIS, 2011, p. 52).

O ser humano passa, pois, a assumir uma posição de destinatário da proteção estatal, mas em igualdade de condições com todos os demais seres humanos, independentemente de raça, cor, religião ou qualquer fator vinculado a aspectos morais.

Outro aspecto a ser considerado em relação à Dignidade da Pessoa Humana é o seu valor imaterial, que, por decorrer da própria essência do seu titular, não 
pode ser mensurado, quantificado; de outro modo, também não é passível de renúncia, alienação (GURGEL, 2010, p. 33). Nesse sentido, segundo Immanuel Kant, apud Ana Celina Bodin (2003, p. 115),

[...] no mundo social existem duas categorias de valores: o preço (preis) e a dignidade (Wurden). Enquanto o preço representa um valor exterior (de mercado) e manifesta interesses particulares, a dignidade representa um valor interior (moral) e é de interesse geral. As coisas têm preço; as pessoas, dignidade.

Há de se considerar que a dignidade da pessoa humana também não resulta da criação artificial dos legisladores constituintes. Estes apenas concebem, elaboram, mecanismos protetivos dos direitos fundamentais vinculados a tal princípio, sendo que tal decorre do reconhecimento de que a pessoa humana tem direito a ter direitos (MORAES, 2003, p. 116).

Anote-se que o Princípio da Dignidade da Pessoa Humana, no contexto atual, é instrumento não apenas de interpretação, mas possui inegável força normativa, sendo fonte de direitos subjetivos. Ademais, se o ser humano passa a assumir uma posição central, o seu bem-estar deve ser assegurado, sobretudo, por intermédio dos Direitos Fundamentais (GURGEL, 2010, p. 33).

No contexto brasileiro, a Constituição de 1988, promulgada após o período da ditadura militar, consagrou o princípio da Dignidade da Pessoa Humana no seu art. $1^{\circ}$, III, concebendo-o como um dos fundamentos da República. Desse modo, "[...] é na dignidade da pessoa humana que a ordem jurídica (democrática) se apóia e constitui-se" (MORAES, 2003, p. 117).

A Constituição vigente foi responsável pela irradiação do multicitado princípio para todo o ordenamento jurídico, o que implicou na desconstrução do conceito privatista dos direitos subjetivos, antes arraigados às normas do Código Civil.

Segundo Ana Celina Bodin de Morais (2003, p. 119), a dignidade da pessoa humana, vista sob esse aspecto, tem supedâneo em quatro postulados:

i) o sujeito moral (ético) reconhece a existência dos outros como sujeitos iguais a ele; ii) merecedores do mesmo respeito à integridade psicofísica de que é titular; iii) é dotado de vontade livre, de autodeterminação; iv) é parte do grupo social, em relação ao qual tem a garantia de não vir a ser marginalizado.

Tais elementos decorrem dos princípios jurídicos da igualdade, integridade física e moral - psicofísica -, da liberdade e da solidariedade. Nesse sentido, embora possam existir conflitos entre os direitos invocados pelos seus titulares, ao se fazer a ponderação, deve prevalecer aquele que estiver alicerçado no princípio da Dignidade da Pessoa Humana. 


\section{Princípio da igualdade}

Conforme explicitado supra, a Dignidade da Pessoa Humana é princípio fundante do ordenamento constitucional brasileiro, servindo tanto como parâmetro interpretativo quanto como instrumento viabilizador dos direitos subjetivos a ele atrelados. Nesse contexto, há de se afirmar que a sua materialização, sobretudo por intermédio dos direitos fundamentais, dentre os quais se destaca, pela inegável relevância, o Princípio da Igualdade, possui, como uma de suas vertentes a vedação ao tratamento discriminatório.

Na visão de Maria Genia Garcia (2005, p. 19), o Princípio da Igualdade “[...] proíbe tratamentos diferenciados repousando não só sobre razões arbitrárias, porque insuficientes e desrazoáveis, mas ainda sobre razões contrárias à dignidade humana".

Historicamente falando, o Princípio da Igualdade foi concebido como uma forma de se afastar privilégios, em um contexto em que as posições sociais eram definidas por questões familiares e patrimoniais. Nesse sentido, "Como comando jurídico inserido em uma Constituição formal, o Princípio da Igualdade aparece, expressamente, pela primeira vez nas Constituições americana, de 1787, e francesa, de 1793, dando início ao constitucionalismo moderno" (GURGEL, 2010, p. 37).

Contudo, a concepção de igualdade de todos perante a lei, reconhecida como igualdade formal ou jurídica (GURGEL, 2010, p. 40), foi-se demonstrando insuficiente, na medida em que desconsiderava as peculiaridades das situações em concreto, sendo inexeqüível para os excluídos socialmente. Desse modo, à igualdade formal associou-se a igualdade material ou substancial, cujo corolário é o tratamento igual para os iguais e desigual para os desiguais.

Nesse cenário, o Estado assumiu uma postura ativa, garantindo não apenas o tratamento igualitário entre as pessoas, mas, a partir da intervenção nas relações privadas, assegurando que todas seriam concretamente tratadas de forma isonômica, merecendo destaque, por esta via, a atuação incisiva dos legisladores na medida em que passaram a se preocupar com a materialização da igualdade nos textos legais.

Outro aspecto a ser ventilado é a necessidade de o Estado contemporâneo, reconhecido como social e democrático, já que viabilizador dos direitos socialmente reconhecidos como relevantes, garantir a participação do povo na construção da igualdade, permitindo a inclusão das minorias nos debates, a possibilidade de todos exercerem o direito ao voto, bem como de assistirem a uma disputa eleitoral partidária em igualdade de condições.

Ressalte-se que a autorização do tratamento desigual, no sentido de viabilização da igualdade material, necessariamente deve estar pautada na anterior constatação de aspectos diferenciadores, sob pena de subversão do seu sentido e fim. Daí a necessidade de que seja exercido um controle em relação ao estabelecimento dos parâmetros. 
Nesse sentido, entende Garcia (2005, p. 17) que:

[...] o princípio da igualdade, além de não ser neutro no momento em que se impõe ou veda certo tratamento jurídico, porquanto está, em si mesmo, [...], fundado num juízo valorativo - o juízo de igualdade - tão pouco é neutro no seu desenvolvimento, uma vez que exige uma justificação com determinados requisitos - desde logo de suficiência e de razoabilidade para esse mesmo tratamento jurídico.

O Princípio da Igualdade deve estar atrelado ao seu aspecto negativo, ou seja, à proibição da discriminação, o que torna imprescindível a realização da distinção entre esta e o tratamento diferenciado (elemento basilar da igualdade material). Segundo Calmom de Passos, citado por Yara Gurgel (2010, p. 49): "Se trato desigualmente os iguais, discrimino. Se trato igualmente os desiguais, discrimino".

Outrossim, Maria Celina Bodin de Morais (2003, p. 126), buscando embasamento em Boaventura de Sousa Santos, ao tratar das tensões dos tempos atuais afirma: "as pessoas e os grupos sociais têm o direito a ser iguais quando a diferença os inferioriza, e o direito a ser diferente quando a igualdade os descaracteriza".

Depreende-se do que foi exposto que o Princípio da Igualdade, na sua vertente material, exige que o Estado, quer exerça a função Jurisdicional, Legislativa ou Executiva, viabilize o tratamento dos jurisdicionados de forma efetivamente isonômica, levando em consideração as suas especificidades, pois, apenas assim, poderá o mesmo promover a concretização dos direitos fundamentais e o respeito à Dignidade da Pessoa Humana.

\section{O PROCESSO COMO COROLÁRIO DOS DIREITOS FUNDAMENTAIS}

Hodiernamente, impõe-se evidente que o processo consiste em instrumento concretizador do desiderato jurisdicional do Estado, o qual tem a sua legitimidade condicionada à necessária vinculação entre o conteúdo das decisões proferidas e o conjunto de Direitos Fundamentais ungidos na Constituição da República (RAGONE, p. 43).

Vislumbra-se, pois, que a legitimação jurídica do processo e, por conseguinte, das decisões judiciais, decorre da sua capacidade em instrumentalizar os Direitos Fundamentais prometidos pela ordem jurídica, de maneira a conferir-lhes aquela especial medida de efetividade que, por si só, "representa a materialização, no mundo dos fatos, dos preceitos legais e simboliza a aproximação, tão íntima quanto possível, entre o dever-ser normativo e o ser da realidade social" (BARROSO, 2000, p. 85).

Nesse sentido, constata-se que a adequada instrumentalização do poder jurisdicional não pode prescindir da prévia consecução de um processo estritamente 
sintonizado, dentre outras, com a garantia basilar da ampla participação das partes, bem como de eventuais interessados, na gradual formação do convencimento do julgador.

Atente-se, neste sentido, que a viabilização de uma irrestrita acessibilidade a todas as partes na realização dos atos, potencial ou efetivamente, construtores $a$ posteriori da coisa julgada, não importando quão imensa sejam as diferenças econômicas entre umas e outras (MIRANDA, 2001, p. 302), revela-se em premissa lógica à concretude do próprio direito fundamental à obtenção da tutela jurisdicional adequada (NERY JÚNIOR, p. 223).

Refletindo sobre a relevância da máxima participação dos cidadãos no processo decisório do Estado como garantia de efetivação, inclusive, dos mais primários direitos de liberdade civil, José Joaquim Gomes Canotilho (1992, p. 543) assevera que:

O cidadão, ao desfrutar de instrumentos jurídico-processuais possibilitadores de uma influência directa no exercício das decisões dos poderes públicos que afectam ou podem afectar os seus direitos, garante a si mesmo um espaço real de liberdade e de efectiva autodeterminação.

Portanto, observada a necessária imbricação entre o processo e os Direitos Fundamentais, de forma que aquele estará despido de legitimidade se desenvolvido ao arrepio destes, imperioso é o reconhecimento de que, no âmbito processual, assim como ocorre no contexto do exercício das demais funções Estatais, a todos deverá ser atribuído tratamento isonômico, a fim de que tenham iguais oportunidades de manifestação, produção de provas e, por conseguinte, persuasão do julgador. Nesse sentido, a Constituição Federal de 1988 prevê, de forma expressa, os princípios do contraditório e ampla defesa (art. $5^{\circ}, \mathrm{LV}$ ), além de garantir que nenhuma lesão ou ameaça a direito serão afastados da apreciação do Poder Judiciário (art. $5^{\circ}, \mathrm{XXXV}$ ).

Contudo, à luz da necessária aplicação do conceito de igualdade material também no contexto processual, a simples previsão constitucional acerca da inafastabilidade do controle jurisdicional e do contraditório e ampla defesa não são suficientes para a garantia de um tratamento efetivamente isonômico entre as partes. Desse modo, "dizer que o acesso à Justiça é um dos componentes do núcleo da dignidade humana significa dizer que todas as pessoas devem ter acesso a tal autoridade: o Judiciário" (BARCELLOS, 2002, p. 293).

Levando-se em consideração a existência de aspectos diferenciadores entre os sujeitos que invocam o Judiciário para a tutela dos seus direitos, as quais se estendem do seu grau de instrução à condição econômica, é preciso que mecanismos viabilizadores do equilíbrio sejam invocados, o que só pode ser obtido a partir do tratamento diferenciado.

Nesse sentido, Jorge Reis Novais (2011, p. 109), citando Dworkin, preleciona: 
[...] a cláusula de igualdade não garante a cada indivíduo o mesmo tratamento ou benefício que é concedido a outros, mas garante-lhe apenas que no processo de formação da vontade política e na concessão de benefícios ou imposição de sacrifícios por parte do Estado ele será tratado com igual preocupação e respeito, ou seja, o princípio da igualdade não lhe garante o mesmo tratamento, mas antes um tratamento como igual.

Tal não implica em beneficiar qualquer das partes no que tange ao direito que pleiteia, nem tampouco de relativizar a imparcialidade do julgador, mas de superar as diferenças, a fim de que seja dada a elas uma autêntica igualdade de chances.

\subsection{Dos ÓbiCes aO diReito FUndaMental de ACESSo À JUSTIÇA}

A vigente Constituição Federal assegura o Direito Fundamental de Acesso à Justiça por meio da norma extraível, em particular, da interpretação combinada entre os incisos XXXV e LXXIV do seu art. $5^{0469}$, cujo espírito, em resumo, aponta para a evidência de que "não basta haver Judiciário; é necessário haver Judiciário que decida. Não basta decisão judicial; é necessário haver decisão judicial justa. Não basta haver decisão judicial justa; é necessário que o povo tenha acesso à decisão judicial justa" (CLEVE, 1993, pp. 50-51).

Reforçando esta teleologia normativo-constitucional, tem-se que o poderdever do Estado em prover o mais irrestrito auxílio jurídico aos que comprovem insuficiência de recursos atualmente ostenta o status de direito-garantia fundamental, adquirindo, neste diapasão, eficácia normativa plena ${ }^{470}$.

Fixados estes pontos, emerge que o enfocado animus normativo não alcança, na esfera da realidade palpável, o grau de materialidade almejado, considerandose, em especial, a notória existência de profundos abismos entre o cidadão lesado em seu patrimônio jurídico e a tutela jurisdicional que lhe é, em tese, destinada pelo ordenamento ora em vigor.

Dentre os inúmeros óbices à efetividade do direito de Acesso à Justiça, encontra-se a questão do consistente custo econômico exigível a priori para a instrumentalização de uma demanda judicial, destacando-se, neste cenário, os elevados va-

\footnotetext{
${ }^{469}$ Constituição da República Federativa do Brasil. Art. $5^{\circ}$ (...) XXXV - a lei não excluirá da apreciação do Poder Judiciário lesão ou ameaça a direito; [...] LXXIV - o Estado prestará assistência jurídica integral e gratuita aos que comprovarem insuficiência de recursos. Disponível em: http://www.planalto.gov.br/ccivil_03/constituicao/constitui\%C3\%A7ao.htm .BRASIL. Constituição Federal. Senado Federal, 1988. Acessado em: 07.03.2013.

${ }^{470}$ Constituição da República Federativa do Brasil.Art. $5^{\circ}, \S 1^{\circ}$ - As normas definidoras dos direitos e garantias fundamentais têm aplicação imediata.Disponível em: http://www.planalto.gov.br/ccivil_03/constituicao/constitui\%C3\%A7ao.htm.BRASIL. Constituição Federal. Senado Federal, 1988. Acessado em: 01.03.2013.
} 
lores que são, costumeiramente, tabelados, atribuídos aos honorários advocatícios ${ }^{471}$, bem como a potencial onerosidade do Princípio da Sucumbência Processual ${ }^{472}$.

Contextualizando tais circunstâncias à luz das evocadas causas de menor complexidade, percebe-se um agravamento, ainda maior, dos obstáculos em análise, tendo em mente que, em muitas situações, o custo, ainda que apenas potencial, do processo poderá vir a exceder o quantum do próprio bem jurídico litigado (CAPELLETTI, 1988, p. 06), esvaziando, dessa forma, tanto o interesse do cidadão em reparar o seu direito violado quanto a utilidade substancial das correlatas tutelas jurídicas.

Acrescente-se que a rotineira morosidade do funcionamento do aparelho judiciário igualmente se mostra capaz de acentuar o ritmo das despesas e eventuais prejuízos processuais, "pressionando os economicamente fracos a abandonar as suas causas, ou a aceitar acordos por valores muito inferiores àqueles a que teriam direito" (CAPELLETTI, 1988, p. 06) e, por esta via, fazendo surgir um déficit cada vez maior na credibilidade do ordenamento jurídico como um todo.

Ao lado disso, tem-se, ainda, que não apenas as condições econômicas desfavoráveis, mas, similarmente, a necessidade de esclarecimento hábil ao discernimento do valor e da dimensão dos próprios direitos, também se configura em grave restrição material à consecução do acesso à Justiça, impossibilitando-se, sob a ótica de tal hipossuficiência jurídico-econômica, a isonomia material, sem a qual o Judiciário se converte num instrumento a serviço do interesse casuístico de uma minoria.

Aprofundando o panorama dos óbices segregadores, de um lado, da sociedade e, de outro, do Judiciário e, por último, da própria Justiça, consta ainda a necessidade da concessão de um tratamento normativo reforçado aos direitos difusos, tais como o meio ambiente e os direitos consumeristas, pois, do contrário, os mesmos restariam carentes de qualquer tutela, interesse ou instrumentos aptos a defendê-los.

Nesse sentido, cumpre anotar que

[...]como fator complicador dos esforços para atacar as barreiras de acesso, deve-se enfatizar que esses obstáculos não podem simplesmente ser eliminados um por um. Muitos problemas de acesso são inter-relacionados, e as mudanças tendentes a melhorar o acesso por um lado podem exacerbar barreiras por outro (CAPELLETTI, 1988, p. 11).

Na concepção de Ana Paula de Barcellos (2002, p. 293), a problemática relativa à efetividade do Acesso à Justiça impõe reflexões relevantes, as quais dizem respeito ao acesso sob o aspecto jurídico, o físico e relativo à pretensão de direito material.

\footnotetext{
${ }^{471}$ Analise-se, ilustrativamente, a Tabela de Honorários da OAB - SP. Disponível em http:// www.oabsp.org.br/tabela-de-honorarios/. Acessado em: 07.03.2013.

472 Código de Processo Civil, arts. 19 e ss. Disponível em http://www.planalto.gov.br/ccivil_03/leis/L5869compilada.htm. Acessado em: 06.03.2013.
} 


\subsection{Das "ONDAS" DE ACESSO À JUSTIÇA}

Adentrando à análise dos mecanismos viabilizadores, no âmbito da hodierna conjuntura jurídico-normativa, da mais ampla e irrestrita acessibilidade, por meio do Poder Judiciário, aos Direitos Fundamentais e, por conseguinte, da Dignidade da Pessoa Humana a eles atrelada, descortina-se, a princípio, a pertinência do desenvolvimento teórico das "ondas" de acesso à Justiça, procedida pelo jurista italiano Mauro Cappelletti (1988, pp. 12-27).

A princípio, consta que a primeira das "ondas" jurídicas em realce objetivou aperfeiçoar a representatividade judicial dos cidadãos mais pobres economicamente, os quais não dispunham dos recursos necessários ao custeio dos serviços advocatícios merecidos por seus direitos carentes de tutela.

Neste panorama, vê-se que os múltiplos sistemas jurídicos do mundo Ocidental, tais como os de países como a Alemanha, a França e a Inglaterra foram gradualmente estabelecendo métodos de patrocínio público à assistência advocatícia buscada por cidadãos pobres, os quais vêm sendo evocados por judicare.

Contudo, a referida dinâmica de financiamento estatal não tem sido suficiente para tutelar a isonomia material tão imprescindível à consecução dos processos judiciários, tendo por alvo, ilustrativamente, a absoluta ausência de uma maior conscientização dos direitos titularizados por cada um para, com isso, solucionar-se a hipossuficiência cultural que tanto limita a eficácia da representatividade judicial financiada sob a égide dos sistemas judicare.

No que toca à segunda "onda" de acessibilidade, observa-se o crescente aprimoramento da tutela direcionada aos direitos difusos ou coletivos, os quais advêm da superação da noção de processo como conflito entre interesses meramente privatísticos, alargando, pois, o seu objeto também a direitos como a adequada proteção ao meio ambiente ecologicamente sustentável.

Destaca-se, aqui, a importância da contínua ampliação do rol de legitimados à propositura de demandas coletivas em prol dos supracitados direitos, cuja abrangência não mais se reduz a órgãos públicos, alcançando sempre mais entidades da sociedade civil, como bem exemplifica a Lei dos Contratos-Padrão na República Federal da Alemanha e a relator-action adotada em países como Inglaterra e Austrália.

Enfim, no que concerne à terceira e mais recente das "ondas" em estudo, tem-se que esta, além de preservar os instrumentos trazidos por meio das duas anteriores, voltou-se para encorajar a implementação de reformas que transcenderam a mera representatividade judicial, abrangendo na modificação de procedimentos; na reestruturação do Poder Judiciário, mediante reorganização dos Tribunais e criação de outros; na profissionalização dos sujeitos atuantes no processo; bem como na reformulação do próprio direito material e do fomento às formas extrajudiciais de solução de conflitos (CAPELLETTI, 1988, pp. 12-27). 


\subsection{Dos instrumentos ViABILIZAdORES DA CONCRETIZAÇÃo DO ACESSO À JUSTIÇA}

Conforme já se tratou anteriormente, a discussão acerca do Acesso à Justiça é extremamente pertinente quando se discute a concretização da Dignidade da Pessoa Humana sob o aspecto da igualdade substancial.

Nesse panorama, há de se vislumbrar os mecanismos que foram e poderão ser adotados para que os sujeitos parciais do processo possam ser tratados de forma efetivamente igualitária.

Preambularmente, destaque-se que, embora o Direito de Acesso à Justiça seja uma via concretizadora dos demais direitos, não há, a princípio, um meio que garanta a sua efetiva instrumentalização substancial (BARCELLOS, 2002, p. 294).

Outrossim, é de se considerar que, além dos obstáculos jurídicos (os quais foram superados, pelo menos em tese, pela previsão constitucional), outros dois óbices ainda se constituem em gravosos desafios, quais sejam, o custo e a desinformação.

No que tange ao custo, há de se reconhecer que o Constituinte, ao prever a gratuidade da Justiça para os que se declararem pobres, instituir as Defensorias Públicas e criar os Juizados Cíveis e Criminais, procurou traspor tal obstáculo. Contudo, há de se questionar acerca da eficácia das normas constitucionais em comento, considerando-se que, na maioria dos Estados brasileiros, os Juizados Especiais não conseguem atender à demanda e as Defensorias Públicas carecem de uma estruturação adequada, não obstante a Emenda Constitucional n ${ }^{\circ}$ 45/2004 tenha outorgado uma ampla autonomia funcional, administrativa e de iniciativa de proposta orçamentária a tais órgãos de auxílio jurídico (PELEJA JÚNIOR, 2011, p. 30).

É válido se destacar também que, em havendo omissão legislativa no que diz respeito à implementação das Defensorias Públicas ou dos Juizados Especiais, será cabível a utilização da Ação Direta de Inconstitucionalidade por Omissão (art. 103, $\S 2^{\circ}$ da CF). Ademais, o Ministério Público, através do ajuizamento de Ações Civis Públicas, igualmente poderá contribuir para a estruturação dessas instituições (BARCELLOS, 2002, pp. 298-300).

Já no que concerne à gratuidade da justiça, percebe-se que houve um inequívoco avanço, destacando-se, ilustrativamente, a hodierna situação da Justiça do Estado do Mato Grosso/BR onde, somente no ano de 2006, houve a concessão dos benefícios da justiça gratuita em 75\% (setenta e cinco) das demandas julgadas (PELEJA JÚNIOR, 2011, p. 30).

Relativamente ao obstáculo de Acesso à Justiça pertinente à informação, vislumbra-se uma dificuldade maior de superação, a qual pressupõe, necessariamente, a consecução de um denso investimento não apenas na educação genericamente considerada, mas também no esclarecimento da população, especificamente, em re- 
lação ao exercício dos seus direitos. De acordo com Ana Paula de Barcellos (2002, p. 300),

A médio e longo prazo, a generalização do ensino fundamental por toda a população brasileira e a inclusão em seu conteúdo curricular de noções sobre o Judiciário e seu papel, o acesso à Justiça e os mecanismos postos à disposição do cidadão para o exercício de seus direitos serão capazes de proporcionar um nível geral ao menos razoável de informação cívica.

Ainda com vistas à superação dos óbices inviabilizadores do Acesso à Justiça, sobreleva-se o instrumento processual da evocada Ação Popular, prevista no art. $5^{\circ}$, LXXIII, da Constituição Federal, in verbis:

LXXIII - qualquer cidadão é parte legítima para propor açãopopular que vise a anular ato lesivo ao patrimônio público ou deentidade de que o Estado participe, à moralidade administrativa, aomeio ambiente e ao patrimônio histórico e cultural, ficando o autor,salvo comprovada má-fé, isento de custas judiciais e do ônus da sucumbência.

Similarmente, a ampliação da utilização das ações coletivas para além da Ação Civil Pública, abrangendo as demandas consumeristas, também vem viabilizando a tutela de direitos que, sem tais instrumentos, estariam despidos de proteção, dada a inércia dos seus titulares. Tal desiderato se coaduna, em tudo, com a segunda onda renovatória, anteriormente explicitada.

Saliente-se, ainda, que o regramento contido no Código de Defesa do Consumidor (sobretudo no que concerne à inversão do ônus da prova), como também na legislação trabalhista (em especial no que tange ao princípio da proteção, à atribuição de capacidade postulatória ao reclamante e a determinação, de ofício, do início dos atos executórios), nada mais são do que o reconhecimento das desigualdades fáticas existentes entre os sujeitos que compõem essas relações jurídicas e, desse modo, a viabilização do Acesso à Justiça, bem como a concretização do princípio da igualdade substancial.

Ressalte-se que a Emenda Constitucional $n^{\circ} 45$ também foi responsável por uma mudança de paradigmas no âmbito da atuação do Poder Judiciário, possibilitando, por meio da implementação de um catálogo de mecanismos efetivadores da atuação do Poder Judiciário, "[...] garantir celeridade na prestação jurisdicional, eliminando nós e gargalos existentes e, na linha divisória da independência dos poderes (art. $2^{\circ}, \mathrm{CRB} / 88$ ) e das cláusulas pétreas (art. 60, $4^{\circ}$, III, CRB/88), caracterizadoras do nosso sistema presidencialista, criou o "polêmico" Conselho Nacional de Justiça" (PELEJA JÚNIOR, 2011, p. 26). Sobre este órgão, bem como acerca da sua singular contribuição para a concretização da dignidade da pessoa humana e dos seus corolá- 
rios, tal como a igualdade substancial, tratar-se-á adiante.

\section{O Conselho Nacional de Justiça como instrumento Viabilizador da DIGNIDADE DA PESSOA HUMANA}

A Emenda Constitucional $n^{\circ} 45$ foi antecedida de um amplo debate em relação ao adequado funcionamento do Judiciário Brasileiro, o qual enfocou, com particular ênfase, a evidência de que, até então, este Poder da República, embora possuísse ingerência em relação às demais esferas do Poder Público, não era objeto de qualquer modalidade de controle externo administrativo-funcional.

Acentue-se, por salutar, que a referida conjuntura institucional terminava por potencializar, sobremaneira, as prerrogativas atribuídas aos magistrados no que concerne à vitaliciedade, inamovibilidade e irredutibilidade de vencimentos. Associado a isso, ainda se evidenciava o crescente descrédito desse Terceiro Poder em relação aos jurisdicionados, sobretudo em virtude da morosidade processual e, por conseguinte, da falta de efetividade material dos seus julgados.

Aprofundando este ponto, evidencia-se que a destacada conjuntura decorria, em particular, da ausência de uma efetiva coesão entre os Tribunais no que tange aos procedimentos administrativos, os quais careciam tanto da formulação de um planejamento estratégico quanto da coordenação de um órgão habilitado a executá-lo.

Sublinhe-se, ainda, que tal problemática refletia de forma direta na instrumentalização do próprio direito de acesso à justiça, visto que, somada aos demais obstáculos anteriormente tratados, induzia a descrença de que, embora se pudesse chegar ao Poder Judiciário, este não daria uma resposta a contento, quer em virtude da morosidade, quer em face da falta de compromisso dos magistrados em relação aos seus deveres funcionais.

Vislumbra-se que a pedra de toque das discussões que, ao final, culminaram na promulgação da citada Emenda foi, de fato, a necessidade de criação de um instrumento viabilizador de estratégias que pudessem ser utilizadas para a solução dos problemas que sempre incomodaram os destinatários da prestação jurisdicional, notadamente a morosidade e a falta de transparência. Percebeu-se, pois, que seria imprescindível a criação de um órgão que, ao atuar nesse sentido, exercesse um autêntico controle externo em relação ao Poder Judiciário.

Destaque-se que, não obstante a experiência vivenciada pelo Brasil durante o Regime Militar, com a criação de um Conselho de Justiça pela Emenda Constitucional $n^{0} 7 / 77$, tal controle até então não havia se materializado (SAMPAIO, 2007, p. 73).

Apenas por ocasião das discussões relacionadas à Constituição de 1988 é que veio à tona o debate atinente a esta problemática, o que dividiu opiniões. Nesse sentido, Saraiva apud Sampaio o entendia como (2007, p. 241): 
[...] um dedo do autoritarismo sobrevivente, além de ser contrário à separação dos poderes, dada a sua composição híbrida ou a inexistência de controle semelhante ao do Executivo e Legislativo, bem como ao princípio federativo, pois era um só para a magistratura federal e dos Estados, a representar, enfim, um retrocesso de mais de cem anos.

Contudo, apenas bem mais tarde é que a discussão frutificou em uma atuação do Poder Constituinte Reformador, sendo possível destacar, dentre outras providências, a criação do Conselho Nacional de Justiça, órgão colegiado e autônomo, de inspiração europeia e natureza administrativo-constitucional (PEDERSOLI, 2011, p. 47).

\subsection{Da caracterizaÇão do Conselho Nacional de Justiça}

A natureza administrativa do mencionado Conselho foi reconhecida, de forma expressa, pela Constituição Federal de 1988, em seu art. 103-B, § $4^{\circ}$. Já o seu respaldo constitucional é inegável, não apenas por ter sido tutelado na Lei Magna, mas pelas atribuições que recebeu para, sobretudo, zelar pela autonomia do Poder Judiciário e exercer o controle dos atos emanados dos magistrados, inclusive de forma concorrente com as Corregedorias, não obstante as discussões suscitadas pela Ação Direta de Inconstitucionalidade $\mathrm{n}^{\circ} 3367$.

Acrescente-se que, desde o momento da sua criação, o CNJ foi alvo de muitas críticas, alicerçadas, em particular, na suposta violação ao princípio da separação de poderes e ao pacto federativo.

Adentrando-se na análise do desrespeito ao princípio da Tripartição de Poderes, tem-se que a sua composição heterogênea, incluindo membros do Poder Judiciário, do Ministério Público, da Advocacia e cidadãos de notável saber jurídico e conduta ilibada (art. 103-B e incisos da Constituição Federal), foi vista como uma agressão à autonomia do Poder Judiciário, o que daria à sua atuação uma conotação mais política do que jurídica. Desse modo, Sampaio (2007, p. 251) aduz que, sob a ótica da ministra Ellen, ser "salutar à democracia que [os Poderes] continuem independentes entre si e complementares na sua atuação convergente à realização da Justiça".

Divergindo da opinião acima, Machado e Cerqueira, citados por Sampaio (2007, p. 251), afirma que “(...) O princípio da separação se nutria mais na idéia de controle do que de independência ou autonomia de cada um deles. Assim, a previsão de um mecanismo a mais de contenção do poder, ainda que de um poder, não podia ser considerada a ele contrária."

Enfatize-se que a existência de membros alheios ao Poder Judiciário não teria o condão de eivar o $\mathrm{CNJ}$ de inconstitucionalidade, haja vista ser a maioria dos 
seus membros proveniente deste mesmo Poder. Outrossim, na esteira de Bermudes (2005, pp. 132-133),

[...] os demais integrantes ou são originários das funções essenciais à justiça ou de membros do povo selecionados pelo Congresso. Conjuga-se assim a legitimidade burocrático-corporativa das duas categorias de imediata interação e cooperação com o Judiciário, diga-se, aferradas ao dever de conselheiro, e não de representantes das duas classes profissionais.

As atribuições do CNJ também suscitaram a discussão acerca da possibilidade de violação do princípio federativo, ante o controle administrativo, disciplinar e orçamentário que esse órgão, de cunho eminentemente federal, passou a exercer em face dos órgãos judiciários estatais. Antes de mais nada é preciso atentar para o fato de que o Poder Judiciário, assim como o Legislativo e o Executivo, são fruto da soberania, não comportando, sob esse viés, compartimentações.

De outra margem, dadas as peculiaridades do exercício da função jurisdicional estatal, lastreada, principalmente, na necessidade de se espancar as situações de instabilidade, mostra-se extremamente necessária a adoção de procedimentos padronizados. Eis o motivo pelo qual a Constituição Federal atribuiu, de forma privativa, à União a competência para legislar sobre matéria processual (art. 22, I, CF). Desse modo, a peculiaridade atinente ao Judiciário no que concerne à relativização do pacto federativo deve se estender ao CNJ. Nesse sentido, aduz Sampaio (2007, p. 256): "Pouco importa de o seu custeio é apenas federal. Em nada modifica seu caráter nacional. É até justificável que assim tenha disposto o constituinte reformador diante da assimetria fiscal de nosso federalismo".

É de se afirmar que a criação do Conselho Nacional de Justiça adveio da necessidade de se proceder a um controle acerca dos atos emanados do Judiciário. Contudo, a função de controle é apenas secundária e instrumental à do planejamento de estratégias que saneiem, ou pelo menos minimizem, as mazelas ínsitas a este Poder da República, possibilitando, dentre outros objetivos, a uniformização das suas práticas institucionais, a transparência das suas atividades lato sensu e a racionalização dos recursos humanos e materiais colocados à sua disposição.

A providência referida supra, considerada de forma isolada, não será suficiente para que a reforma do Judiciário ocorra em sua plenitude. Contudo, mesmo considerando as limitações impostas constitucionalmente ao CNJ, este tem servido de intermediário entre o povo e o Judiciário, o que tem contribuído enormemente para o fortalecimento da democracia, bem como para o aperfeiçoamento da prestação da tutela jurisdicional.

Importa frisar que o Supremo Tribunal Federal endossou o caráter de essencialidade do $\mathrm{CNJ}$, ao refutar a alegação de inconstitucionalidade do próprio Conselho e de alguns outros dispositivos constitucionais a ele pertinentes, feita pela 
Associação Brasileira dos Magistrados (AMB), no contexto da Ação Direta de Inconstitucionalidade $\mathrm{n}^{\circ} 3367$, de relatoria do Ministro Cesar Peluzo.

Há de se enfocar, ainda, que a atuação do órgão, ao estabelecer metas, emitir resoluções, recomendações e traçar um perfil do Poder Judiciário, tem contribuído para a duração razoável do processo e a efetividade da prestação jurisdicional, propiciando, enfim, uma ambiência adequada à garantia do acesso à justiça, à duração razoável do processo, efetivação da igualdade substancial no contexto processual e, por conseguinte, à proteção da dignidade humana dos sujeitos nele envolvidos.

\subsection{DAdOS ESTATÍSTICOS QUE CORROBORAM A IMPRESCINDIBILIDADE DA ATUA- Ção Do CNJ}

Conforme afirmado alhures, o Conselho Nacional de Justiça, desde a sua criação, tem sido alvo de questionamentos, que se estendem da sua constitucionalidade à amplitude das suas atribuições.

No entanto, há de se reconhecer que essas discussões são indiciárias de que o órgão tem atuado de forma efetiva, pelo menos no que concerne à realização de um diagnóstico do Poder Judiciário e, nesse sentido, na aproximação entre esse Poder e a sociedade.

Corroborando o afirmado supra, afirme-se que, desde o ano de 2004, o multicitado Conselho tem divulgado dados relativos à atuação do Judiciário brasileiro, compilados no Relatório Anual "Justiça em Números" tem sido aperfeiçoado, através do refino dos dados e da contribuição cada vez mais ampla dos Tribunais Brasileiros, que se responsabilizam pelo envio das informações.

Trata-se de uma iniciativa muito relevante, na medida em que não se restringe à apresentação de dados estatísticos, mas ao diagnóstico dos pontos críticos e à indicação de medidas que viabilizarão melhorias. Ademais, instrumentalizam a aferição do cumprimento das metas estabelecidas pelo CNJ e, por conseguinte, a evolução do esforço empreendido pelos Tribunais no sentido de viabilizar a superação de problemas como a morosidade e a escassa efetividade processual, os quais, inevitavelmente, implicam em séria limitação do Acesso à Justiça.

Ilustrando alguns dos resultados já obtidos por parte do Conselho Nacional de Justiça, faz-se imprescindível observar os dados catalogados na Edição 2012 do Relatório Justiça em Números, o qual se encontra disciplinado pela Resolução $\mathrm{n}^{\circ} 76$ - CNJ e, por sua vez, compõe o Sistema de Estatística do Poder Judiciário (SIESPJ), em cuja abrangência alcança todo o rol de Tribunais judiciários presentes no território pátrio.

Especifique-se, ainda, que o objeto do Relatório em referência aborda diversos e relevantes aspectos da realidade funcional do Poder Judiciário, tais como: insumos, dotações e graus de utilização; litigiosidade; acesso à justiça e perfil das demandas.

${ }^{473}$ Disponível em http://www.cnj.jus.br/cidadao/publicacoes. Acessado em: 04.03. 2013. 
Frise-se também que, contrariamente aos demais dados, os quais somente são repassados anualmente ao longo do período compreendido entre 10 de janeiro e 28 de fevereiro do ano subsequente, as informações atinentes à litigiosidade são sempre colhidas em ritmo semestral, mais especificamente, no período entre 10 de julho a 31 de agosto (dados do primeiro semestre) do ano-base e no período de 10 de janeiro a 28 de fevereiro do ano seguinte ao ano-base (dados do segundo semestre).

Fixados estes pontos, cumpre ressaltar que, por força dos limites ínsitos ao seu próprio objeto, a presente reflexão se restringirá, exclusivamente, a perquirir acerca dos dados relativos aos Tribunais de Justiça dos Estados, os quais dizem respeito ao diagnóstico identificado à luz do regramento supramencionado ao longo do ano de 2011.

Partindo-se dessas premissas, constata-se que, durante o supracitado período, a quantidade de processos baixados foi a maior verificada nos últimos três anos. Outrossim, a taxa de congestionamento, que é a relativa aos processos acumulados, cujo andamento está lento ou simplesmente obstado, foi alvo de uma suave redução ( $0,52 \%)$, a qual foi acompanhada de outro ponto positivo, consistente no aumento da quantidade de processos julgados por magistrado, que aumentou em 6,3\% em relação a 2010.

De outro lado, verifica-se, como aspectos negativos, que, desde o ano de 2009, o estoque dos processos vem aumentando. Ademais, a comparação entre a quantidade de processos baixados e novos indica uma curva decrescente, o que revela um potencial de congestionamento. Por fim, desde 2009, constata-se uma diminuição da quantidade de processos julgados.

Das estatísticas acima se extrai que ainda há muito o que avançar no que concerne à eficaz administração das demandas processuais. No entanto, não se pode negar que um grande passo foi dado, sobretudo no que diz respeito à transparência em relação à atuação do Poder Judiciário, o que, sem sombra de dúvida, contribui para o aprimoramento da prestação jurisdicional, do próprio Direito Fundamental de Acesso à Justiça e, por conseguinte, da dignidade da pessoa humana no âmbito da atuação jurisdicional estatal.

\section{Conclusão}

O princípio da Dignidade da Pessoa Humana é corolário do Estado Constitucional de Direito, sendo reconhecido hodiernamente como tal pelas Constituições de vários países do mundo. Como decorrência disso, tem-se que a interpretação das normas constitucionais e infraconstitucionais deverá pautar-se na garantia desses direitos arraigados à condição humana.

Há de se ponderar, contudo, que o status adquirido pelo princípio acima mencionado não se restringe ao plano teórico, formal ou interpretativo, devendo viabilizar a efetiva concretização dos direitos inerentes ao homem na sua dimensão 
mais profunda, o que se dá, comumente, por intermédio da efetivação dos direitos fundamentais, dentre os quais o direito/princípio da Igualdade.

Insta relevar que o princípio da Igualdade, concebido na sua dimensão positiva, determina que todos deverão ser tratados de forma isonômica. Já no seu aspecto negativo, veda a discriminação. Contudo, a fim de que possa instrumentalizar o tratamento paritário entre os sujeitos de direitos, seja no âmbito público ou privado, a Igualdade concebida de maneira formal ou perante a lei não é suficiente, na medida em que desconsidera os elementos individualizantes dos seus titulares, o que impulsiona a invocação da Igualdade no sentido substancial ou material, por meio da qual os iguais são tratados igualmente e os desiguais desigualmente.

No âmbito processual, a fim de que as partes tenham as mesmas oportunidades, é imprescindível que o conceito de igualdade substancial seja aplicado. Neste cenário, além de se viabilizar o acesso à justiça, transpondo todos os obstáculos (jurídicos, econômicos ou sociais) que a inviabilizam, é imprescindível que outros mecanismos sejam vislumbrados e efetivados, tudo em prol do espancamento das diferenças e da consolidação do equilíbrio.

A própria Constituição Federal tratou de regulamentar meios viabilizadores da igualdade substancial no âmbito processual, em um claro reconhecimento de que a mera previsão da inafastabilidade do controle jurisdicional e do contraditório e ampla defesa não são suficientes para a garantia efetiva do acesso à justiça. Desse modo, estabeleceu a gratuidade da Justiça para os que se declararem pobres na forma da lei; previu a criação das Defensorias Públicas e dos Juizados Especiais.

Outrossim, a Ação Popular, a Ação Civil Pública, as ações coletivas no âmbito do Direito do Consumidor, além do regramento específico deste catálogo de direitos consubstanciado no Código de Defesa do Consumidor, bem assim dos princípios e regras pertinentes ao Direito do Trabalho, constituem elementos viabilizadores não apenas do Acesso à Justiça, mas da Igualdade substancial no âmbito processual.

Contudo, há de se destacar que, não obstante os avanços já consolidados, resta um longo caminho a ser percorrido, visto que, a exemplo das Defensorias Públicas, as quais ainda não foram efetivamente instaladas em muitos estados do Brasil, há um grande distanciamento entre a previsão normativa e a sua concretização fática. Eis o que justifica as inovações introduzidas pela Emenda Constitucional $n^{\circ}$ 45, que promoveu uma verdadeira reforma no âmbito do Poder Judiciário, sobretudo em relação à criação do Conselho Nacional de Justiça, cujo precípuo fim é a viabilização de uma atuação mais efetiva e justa do Poder Judiciário Brasileiro, desiderato este que, em última instância, revela-se em sustentáculo do próprio princípio da Dignidade da Pessoa Humana.

Há de se destacar que o órgão acima referido, desde a sua criação, tem sido alvo de muitas críticas, o que ensejou, a princípio, a discussão em relação à sua constitucionalidade e, posteriormente, no que tange aos poderes e limites destes 
conferidos constitucionalmente. Tal ordem de coisas deve-se, sobretudo, à resistência que os membros do Poder Judiciário têm em relação à realização de um controle externo sobre a sua atuação.

No entanto, os dados estatísticos explorados no presente artigo demonstram que, no mínimo, a atuação do CNJ contribui sobremaneira para que sejam diagnosticados os principais problemas que permeiam a atuação do Poder Judiciário Brasileiro, o que poderá servir de parâmetro para a busca de instrumentos concretos de superação. Outrossim, o estabelecimento de metas e a fiscalização do seu cumprimento através de relatórios,potencialmente viabilizará a constatação das regiões mais críticas em termos de congestionamento, tornado possível a adoção de medidas específicas em relação à destinação de juízes, servidores e demais recursos que viabilizem o suprimento das demandas locais.

Ressalte-se, por fim, que o órgão acima mencionado, ao agir no sentido de traçar diagnósticos e determinar o cumprimento de metas, não solucionará por completo toda a problemática que envolve o Poder Judiciário no Brasil. No entanto, é inegável que, a partir da sua contribuição para que tal poder se torne mais transparente e preocupado com a sua missão constitucional, aproximando-se dos destinatários do serviço que presta e que, de forma indireta, legitima a sua existência, sem dúvida contribui para a consecução do Princípio da Dignidade da Pessoa Humana a partir do seu acesso a um instrumental viabilizador da proteção aos bens jurídicos dos quais é titular, o que, por si só, arrefece as reservas que, de certo modo, tentam diminuir a relevância e força do Conselho Nacional de Justiça.

\section{REFERÊNCIAS}

BARCELLOS, Ana Paula de. A eficácia dos princípios constitucionais: o princípio da dignidade da pessoa humana. Rio de janeiro: Renovar, 2002.

BARROSO, Luís Roberto.O Direito Constitucional e a Efetividade de suas Normas. 4. ed.ampl. e atual. Rio de Janeiro: Renovar, 2000.

BERMUDES, Sérgio. A reforma do Judiciário pela Emenda Constitucional n. 45. Rio de Janeiro: Forense, 2005.

CANOTILHO, José Joaquim Gomes. Direito Constitucional. Coimbra, Almedina, 1992.

CAPPELLETTI, Mauro; GARTH, Bryant. Acesso à Justiça. Tradução de Ellen Gracie Northfleet. Porto Alegre: Sérgio Antônio Fabris, 1988.

CLÉVE, Clémerson Merlin. Temas de Direito Constitucional e de Teoria do Direito. São Paulo: Editora Acadêmica, 1993.

BRASIL. Lei n. ${ }^{\circ}$ 5869, de 11 de janeiro de 1973. Código de Processo Civil. Disponível em: http://www.planalto.gov.br/ccivil_03/leis/L5869compilada.htm. Acessado 
em: 01.03.2013.

BRASIL. Constituição (1988). Constituição da República Federativa do Brasil. Brasília, DF: Senado; 1988. Disponível em: http://www.planalto.gov.br/ccivil_03/constituicao/constitui\%C3\%A7ao.htm. Acessado em: 03.03.2013.

GARCIA, Maria Glória. Estudos sobre o Princípio da Igualdade. Coimbra, Almedina, 2005.

GURGEL, Yara Maria Pereira. Direitos Humanos, Princípio da Igualdade e não Discriminação - Sua Aplicação às Relações de Trabalho. São Paulo: LTR, 2010.

Justiça em Números. Disponível na internet: http://www.cnj.jus.br/cidadao/publicacoes. Acessado em: 04.03.2013.

MIRANDA, Jorge. A tutela jurisdicional dos direitos fundamentais em Portugal. In GRAU, Eros Roberto; GUERRA FILHO, Willis Santiago (org.). Direito constitucional: estudos em homenagem a Paulo Bonavides. São Paulo: Malheiros, 2001.

MORAES, Maria Celina Bodin de. O conceito de dignidade da pessoa humana: substrato axiológico e conteúdo normativo. In SARLET, Ingo Wolfang (Org.). Constituição, direitos fundamentais e Direito Privado. Porto Alegre: Livr. do Advogado Ed., 2003.

NÉRY JÚNIOR, Nelson; NÉRY, Rosa Maria de Andrade.Constituição Federal Comentada e Legislação Constitucional. 3. ed. São Paulo: Ed. Revista dos Tribunais.

NOVAIS, Jorge Reis. Os princípios constitucionais estruturantes da República Portuguesa. Coimbra, 2011.

PELEJA JÚNIOR, Antônio Veloso. Conselho Nacional de Justiça e a Magistratura Brasileira. 2. ed. Curitiba: Juruá, 2011.

PEDERSOLI, Christiane Vieira Soares. Conselho Nacional de Justiça: atribuição regulamentar no Brasil e no direito comparado. Belo Horizonte: Fórum, 2011.

RAGONE,Alvaro Pérez.Contornos de lajusticiaprocesal (procedural fairness): lajustificación ética delproceso civil. Curitiba: Genesis, 2006.

SAMPAIO, José Adércio Leite. O Conselho Nacional de Justiça e a Independência do Judiciário. Belo Horizonte: Del Rey, 2007.

Tabela de Honorários da OAB - SP. Disponível em http://www.oabsp.org.br/tabelade-honorarios/. Acessado em: 01.03.2013. 